\title{
Discurso, ideología y medios: El periodismo de libre mercado en Chile
}

\section{Discourse, ideology and media: Free market journalism in Chile}

\author{
Pamela Soledad Romero Lizama pamela.romero@ucn.cl \\ https://orcid.org/0000-0003-0191-128X \\ Escuela de Periodismo; Facultad de Humanidades; Universidad Católica del Norte, Chile
}

Resumen

Este artículo reflexiona en torno a cómo la ideología ha influido en los cambios que se han dado en los medios de comunicación en Chile, principalmente centrado en el duopolio de la prensa. En este sentido, se aborda la forma en que el discurso de los medios se convierte en una herramienta de transmisión ideológica. Para ello se presenta como ejemplo la manera en que la prensa chilena fue mutando a una industria controlada por el libre mercado y el avisaje publicitario, principalmente fomentada por la dictadura y los gobiernos posteriores. 
Palabras Clave: discurso; ideología; medios de comunicación; libre mercado; Chile.

\section{Abstract}

This article reflects on how ideology has influenced the changes that have taken place in the media in Chile, mainly focused on the duopoly of the press. In this sense, the text approaches the way in which the discourse of the media becomes a tool of ideological transmission. For this, the example of how the Chilean press was mutating into an industry controlled by the free market and advertising, mainly promoted by the dictatorship and subsequent governments, is presented.

Keywords: discourse; ideology; media; free market; Chile.

\section{Introducción}

El presente artículo pretende reflexionar sobre las influencias de la ideología sobre los discursos de los medios de comunicación, principalmente en la prensa. Se propone primero un abordaje a algunas nociones de discurso y cómo éste se relaciona directamente a las ideologías en los medios de comunicación. Posteriormente, se presentará el caso del sistema de prensa chileno, que está muy concentrado en pocos dueños, y del que se destaca un duopolio, que fue potenciado durante la dictadura militar y que maneja la mayoría de las publicaciones en la actualidad. Desde allí, se profundizará sobre la manera en que el periodismo escrito en Chile fue mutando a una industria de la información controlada por el libre mercado, con discursos periodísticos que no aportan a la formación de la ciudadanía, sino más bien a conseguir lectores para aumentar el avisaje publicitario. Finalmente, y a modo de conclusión, se presentan algunas ideas en relación al futuro del periodismo y sus posibilidades. 


\section{Discursos ideológicos en los medios de comunicación}

Antes que todo, lo que se propone es revisar algunas nociones de discurso, específicamente las posiciones del lingüista Teun van Dijk y del filósofo Michel Foucault. Van Dijk (2006) aborda el discurso desde una perspectiva multidisciplinaria, que involucra enfoques lingüísticos, sociales, cognitivos y culturales. El autor entiende el discurso como un evento comunicativo específico y complejo, que involucra a una cierta cantidad de actores sociales como emisores o receptores.

Estamos rodeados por discursos, y constantemente producimos y recibimos discursos, o nos vemos obligados a consumirlos. Donde sea que encontremos un mensaje compuesto por enunciados y que se de en un contexto específico, ahí hay discurso. Pero no todos tenemos las mismas posibilidades de emitir discursos y nuestros discursos no tienen la misma posibilidad de recepción. Al respecto, Foucault propone que:

en toda sociedad la producción del discurso está a la vez controlada, seleccionada y redistribuida por un cierto número de procedimientos que tienen por función conjurar los poderes y peligros, dominar el acontecimiento aleatorio y esquivar su pesada y temible materialidad (1992, p. 12).

Los discursos son campos de batalla, y aquellos que dominan la sociedad dominan los discursos: lo que se debe callar, lo que se puede decir, quiénes pueden decirlo y a quiénes hay que decirlo. Foucault sostiene que el discurso es, en sí mismo, un objeto de deseo, que es al mismo tiempo «aquello por lo que, y por medio de lo cual se lucha, aquel poder del que quiere uno adueñarse» (1992, p. 13). El discurso es poder y es también aquello que nos permite obtener el poder. Es un poder que va más allá de un dominio sobre los recursos económicos, sino que abarca al saber: la apropiación de la información. Hay poder en el conocimiento, el poder de poseer el discurso verdadero, o la pretensión científica u objetiva de nuestro punto de vista.

Sostiene Foucault que existirían dos especies de discursos en nivelación en las sociedades actuales. El primer tipo de discurso es el que se dice en las conversaciones, discursos que serían pasajeros y que no tendrían mayores repercusiones. El segundo tipo de discurso es mucho más importante. Corresponde a aquellos discursos que son capaces de generar nuevos discursos "que los reanudan, los transforman o hablan de ellos, en resumen, discursos que, indefinidamente, más allá de su formulación, son dichos, permanecen dichos, y están todavía 
por decir» (1992, p. 22). Estos son los discursos dialogantes que trascienden y componen nuestro sistema cultural.

Foucault propone analizar los discursos con toda la carga de poder que conllevan y su peligrosidad, ya que no se pueden mantener ni aplicar sin coacción, y entenderlos «como una violencia que hacemos a las cosas, en todo caso como una práctica que les imponemos» (1992, p. 45).

Los discursos son importantes a la hora de estudiar la reproducción de las ideologías. En este caso, los discursos que nos interesan son los de los medios de comunicación y, paralelamente, por ideologías entenderemos a los «sistemas políticos o sociales de ideas, valores o preceptos de grupos u otras colectividades y (que) tienen la función de organizar o legitimar las acciones del grupo» (van Dijk, 2006, p. 16).

Asumimos que el discurso forma parte de las ideologías, y que éstas se relacionan a los usos del lenguaje. Según van Dijk (2006), las funciones principales de las ideologías en la sociedad son el ocultamiento, la legitimación y la manipulación (entre otras) y éstas corresponden a prácticas discursivas. Si bien, las ideologías no se expresan solamente por medio del discurso, ésta es la forma fundamental en la que las ideologías se reproducen. Probado está, en nuestros días, que los discursos no son neutrales. Al respecto, Pedro Santander pone énfasis en su opacidad a la hora de analizarlos:

hoy sabemos que el lenguaje no es transparente, los signos no son inocentes, que la connotación va con la denotación, que el lenguaje muestra, pero también distorsiona y oculta, que a veces lo expresado refleja directamente lo pensado y a veces sólo es un indicio ligero, sutil, cínico (2009, p. 135).

Ante discursos que pudieran parecer banales a simple vista, una lectura desde la ideología permitiría decodificar su verdadero sentido. Se entiende que todos los discursos analizados según un filtro ideológico se verán atiborrados de sentido, revelando los intereses de la sociedad de la que este discurso proviene (Mattelart, Piccini y Mattelart, 1976).

Pero ¿cómo podemos identificar la ideología dentro de los discursos? Como ya se mencionaba, el discurso ideológico hace referencia a los conflictos entre grupos. La ideología de un grupo nos habla de una relación polarizada, en la que se identifica con claridad un nosotros y un ellos. Resulta necesario entender a las ideologías como representaciones sociales. Y para conocerlas necesitamos saber cómo se presentan los miembros del grupo a sí mismos y a los demás, a los de afuera. 
Nosotros está representado de una forma positiva y ellos de manera negativa. Por ejemplo, en una ideología racista, nosotros somos superiores a ellos en consideración a nuestra raza. De esta forma, se hace exclusión hacia el grupo de fuera, los otros, desde el grupo de dentro. Los individuos que quedan fuera de nuestros parámetros de normalidad, del nosotros, son aislados socialmente.

Para van Dijk (2006), la auto representación positiva y la representación negativa de los otros es una característica propia de las ideologías. Entonces, las ideologías tendrían un esquema de grupo en el que se verían reflejados nuestros intereses. Van Dijk (2006) afirma que la estrategia del discurso ideológico es la siguiente: 1) poner énfasis en nuestros aspectos positivos; 2) poner énfasis en sus aspectos negativos; 3) quitar énfasis de sus aspectos positivos; y 4) quitar énfasis de nuestros aspectos negativos.

En palabras de Julio García (2013), la ideología debe ser concebida de la mano con los discursos y no como un cuerpo separado, presente en todos los niveles y expresiones culturales, con la capacidad de construir consenso social. Este autor sostiene que el periodismo no tiene por sí mismo un sello ideológico:

El periodismo (...) no tiene un sello político o ideológico a priori. Éste se lo impone la clase o grupo social que hace uso de él. Es un instrumento o herramienta que ha construido la sociedad, como parte del conocimiento y transformación del mundo. Los sellos, en todo caso, son temporales y cambiantes (2013, p. 37).

\section{Periodismo y discurso público}

Existe un ideal de periodismo, y es que éste sea lo más plural y verídico posible y que pueda influir de manera positiva en el desarrollo de la sociedad. Los medios de comunicación de carácter informativo, y su principal producto (las noticias) se nos presentan como objetivos y neutrales y es allí donde radica su potencial peligrosidad. Al no estar conscientes de que estamos recibiendo un adoctrinamiento cultural e ideológico, somos más permeables a la persuasión e imposición de las ideas de quienes ostentan el poder.

Por ejemplo, Héctor Vera, desde una lectura crítica de la construcción de las noticias, denuncia que hay intencionalidad y desviaciones en su estructura: «Sistemáticamente, la mayoría de los medios se colocan de lado de las autoridades y de la "normalidad social", desfavoreciendo las fuerzas que buscan los cambios sociales» (2008, p. 298).

En efecto, no son los medios de comunicación los únicos discursos a los que estamos expuestos día a día, y que pueden ir modificando nuestras conductas y nuestros valores. Pensemos, por ejemplo, en las conversaciones cotidianas con nuestros amigos y familiares, en 
la literatura, las artes, la publicidad, etc. Pero por su masividad y su supuesto carácter de verdad, los medios de comunicación están ahí, omnipresentes, disponibles incluso las 24 horas del día para hacernos sentir acompañados, entretenidos o informados. Nos guste o no, los medios juegan un rol fundamental a la hora de transmitir y perpetuar estereotipos. Y su verticalidad unidireccional no puede ser cuestionada o respondida por el público. Gracias a las nuevas tecnologías ha habido algunos avances en este sentido, pero, en su mayoría, los medios de comunicación, especialmente los escritos, perpetúan un modelo de relación donde no hay retroalimentación.

Considerando lo anterior, es importante entender las noticias como fotografías de la actualidad, pero, a la vez, entender que éstas también «Son discursos de algunos (subjetividades) que se hacen públicos para todos (objetividades)»(Romero, 2013, p. 872). Y quienes hacen públicos sus propios discursos como los dominantes en la sociedad actual son aquellos más poderosos, es decir, las elites. Y las personas comunes solamente tenemos control sobre nuestras propias subjetividades, las que no estamos en condiciones de hacer públicas.

Por su parte, las elites tienen diversos canales para controlar los discursos que se hacen públicos, dirigiendo, por ejemplo, los discursos gubernamentales, empresariales, intelectuales, $y$, por supuesto, los mediáticos. Por tanto, hay que entender a las noticias en un contexto que las relaciona directamente a las ideologías y al poder.

A pesar del espíritu crítico y democrático con el que nació la prensa, para difundir las ideas de la opinión pública, generar debates y fiscalizar a los gobernantes en el período de la llustración, somos testigos de que el periodismo ha apoyado siempre a las clases dominantes, y de que son sus voces, creencias, ideas, intereses y valores (ideología) los que se hacen públicos para todos. De esta manera, se generan las condiciones para cometer abusos hacia los más desprotegidos en términos culturales y económicos. Aunque esto se esconde tras la fachada de ser los portadores de la verdad.

Pascual Serrano asegura que el funcionamiento empresarial de los medios en la actualidad ha generado dos clases de ciudadanos:

una gran mayoría que consume grandes medios de comunicación de forma acrítica y se convierte en carne de manipulación informativa y una élite política e intelectual que logra comprender las claves del mundo. De esta última, una parte utiliza esa información para aprovecharse y otra -la crítica- se ve obligada a convivir con la impotencia de no lograr que su mensaje llegue a la comunidad ciudadana (2012, p. 16). 
Para Serrano, los medios no mienten, pero si manipulan de diferentes maneras las informaciones que nos hacen llegar. La prensa está intentando todo el tiempo hacernos creer que no nos mienten y, aparentando que nos informan, nos van desinformando: «su función no es informar sino desinformar, no es fomentar el análisis y el debate democrático, sino diluirlo y silenciarlo» (2012, p. 73).

Para Pierre Bourdieu, los periodistas ocupan un lugar importante dentro de la escala social, ya que, a pesar de ser dominados, tienen control (aunque restringido por sus superiores) sobre los discursos:

\begin{abstract}
Los periodistas -habría que decir el campo periodístico- deben su importancia en el mundo social a que ostentan el monopolio de hecho de los medios de producción y difusión a gran escala de la información, mediante los cuales regulan el acceso de los ciudadanos de a pie, así como de los demás productores culturales, científicos, artistas, escritores, a lo que a veces se llama «el espacio público», es decir a la difusión en gran escala (1997, p. 67).
\end{abstract}

Para el autor, los periodistas llegan a ejercer una censura inconsciente al escoger los acontecimientos noticiables, puesto que «No hay discurso (análisis científico, manifiesto político, etcétera) ni acción (manifestación, huelga, etcétera) que, para tener acceso al debate público, no deba someterse a esta prueba de selección periodística» (Bourdieu, 1997, p. 68). Bourdieu también descarta la existencia del periodista como un ente concreto. Es más bien un concepto abstracto, en el sentido de que existen diferentes tipos de personas que optan por hacer del periodismo su oficio, cada uno con sus propias características, según nacionalidad, sexo, edad, medio, nivel educacional, etc. Por tanto, Bourdieu pone énfasis en la dificultad de generalizar en el mundo del periodismo, un mundo empresarial repleto de presiones, hostilidades, tensiones y competencia.

En medio de toda esta puesta en escena, los periodistas se atribuyen la capacidad para seleccionar acontecimientos y convertirlos en noticias. Juegan, entonces, un doble papel: por un lado, el periodista es una persona común, pero enfrenta la realidad al mismo tiempo como participante y como un observador crítico de ésta, desarrollando ideas, vinculando los hechos y sus respectivos contextos, produciendo discursos noticiosos y dotándolos de significados. En síntesis, el periodista es un mediador entre el público y su realidad social.

Bien lo señala Miquel Rodrigo Alsina (2005, p. 13): «Los periodistas son, como todas las personas, constructores de la realidad de su entorno. Pero además dan forma de narración a esta realidad y, difundiéndola, la convierten en una realidad pública». La noticia, como discurso 
público, se sustenta de creencias compartidas y legitima estas creencias a través de su aparición en los medios de comunicación, dando paso a una relación dialéctica de construcción de la realidad.

\section{El duopolio de la prensa en Chile}

Como sucede en la mayoría de los medios de comunicación masiva en América Latina y el mundo, la prensa en Chile es un nicho de negocios. Los periódicos más leídos y vendidos en Chile son propiedad de grandes empresarios representantes de la oligarquía nacional, quienes hacen uso de su influencia sobre la opinión pública para imponer sus posiciones ideológicas y obtener beneficios económicos. En palabras de María Olivia Mönckeberg (2013, p. 407): «La prensa se encuentra hoy casi exclusivamente en manos de la derecha económica y política, que al final de cuentas termina siendo lo mismo".

Se distinguen principalmente dos empresas periodísticas: El Mercurio Sociedad Anónima Periodística, fundada en el año 1900 y perteneciente a la conservadora dinastía Edwards, y Consorcio Periodístico de Chile Sociedad Anónima (Copesa), fundada en 1953 por la familia Picó Cañas, y perteneciente desde 1989 a las sociedades del empresario Álvaro Saieh, su actual dueño.

Según un estudio de concentración de medios en Chile, desarrollado el 2015 por Luis Breull con fondos del Consejo Nacional de Televisión, el grupo El Mercurio posee un total de 74 medios de comunicación, con 23 diarios a lo largo del territorio nacional y 16 revistas y periódicos, además de 33 medios digitales. Por su parte el grupo Copesa posee 46 medios de comunicación, contando 4 diarios, 13 revistas y periódicos y 22 medios digitales. De acuerdo a la misma investigación, la audiencia online también se concentra en el grupo El Mercurio y el grupo Copesa, con un 31\% y 10\%, respectivamente. El Grupo el Mercurio y el Grupo Copesa presentan alta concentración en lo que se refiere a propiedad de medios, ingresos, audiencia, hegemonía territorial e inversión publicitaria.

Muy pocos diarios independientes de regiones pueden mantener una competencia frente a estos gigantes de las noticias, puesto que no se encuentran en igualdad de condiciones. Por otra parte, la prensa estatal, que podría haber contribuido a mantener cierto equilibrio, vio su fin en el año 2010, cuando el diario La Nación decidió finalizar su versión impresa, para decantar en una publicación online. Vale destacar que en Chile no existe una Ley de Medios que pueda regular la libertad de prensa, la concentración o el pluralismo en sistema informativo nacional, aunque se ha señalado desde la academia y el Colegio de Periodistas que urge una normativa de este tipo para democratizar el derecho a la comunicación pública en nuestro país. 
Para Ken Dermota (2002), la peligrosidad del duopolio radica en que no representa los intereses públicos, sino, más bien, intereses particulares. Dueños de la opinión dominante en la prensa, los propietarios de estos medios de comunicación utilizan su influencia social para obtener beneficios económicos bajo la excusa del libre mercado.

Este duopolio informativo, perteneciente económicamente a dos empresas, pero ideológicamente a una misma línea de pensamiento político (un monopolio discursivoideológico), se configuró a partir de la dictadura militar de Augusto Pinochet, entre 1973 y 1990 , en la que desde un principio se silenció a todos los medios de comunicación disidentes (de izquierda y centro) y se privilegió a El Mercurio y Copesa, representantes tradicionales de la derecha conservadora.

El informe del Comité Church (1975) del Congreso de Estados Unidos, da cuenta de que Agustín Edwards recibió ayuda económica de la Agencia Central de Inteligencia (CIA) para desestabilizar al régimen de Salvador Allende. No es de extrañar entonces que en sus páginas se alarmara a la población, y que, una vez que los militares usurparan el poder, manipularan la información según sus intereses y justificaran los crímenes contra los derechos humanos, como queda demostrado en diversos trabajos de investigación y análisis. Como ejemplos prácticos, se pueden citar el documental de Ignacio Agüero y Fernando Villagrán El Diario de Agustín (2008) y el libro homónimo editado por Claudia Lagos, que reúne investigaciones de periodistas de la Universidad de Chile (2009, Editorial LOM). Considerando hechos y actitudes concretas, Lidia Baltra señala respecto a los principales periódicos de El Mercurio y Copesa:

\begin{abstract}
El Mercurio y La Tercera se constituyeron en los medios predilectos de la dictadura militar. Además de ser los únicos dos (periódicos) permitidos el día siguiente al golpe de 1973 y los únicos sobrevivientes durante varios meses, a comienzos de los 80 recibieron un millonario apoyo financiero estatal para salir de las deudas y crecer. La Tercera modernizó su infraestructura y equipos, y El Mercurio terminó su actual edificio en Lo Curro y se computarizó (2012, p. 26).
\end{abstract}

Indudablemente, el Gobierno Militar y el duopolio compartieron una misma postura ideológica, que incluía la imposición de un sistema de economía neoliberal en Chile, promovida y aplicada por los graduados chilenos de la Universidad de Chicago y egresados de la Pontificia Universidad Católica de Chile, conocidos como los Chicago Boys. Conviene recordar que Chile fue el primer lugar en el mundo donde se aplicaron las teorías de la economía de libre mercado. Ligado a este último punto, Dermota recalca la importancia de estos diarios, en especial de El Mercurio, el decano de la prensa: «El Mercurio, más que ninguna otra institución 
civil, ayudó a poner a los militares en el poder, a proporcionar equipo humano al régimen y a mantener a Pinochet en el poder durante más de 16 años» (2002, p. 56).

En 1980, Juan Pablo Cárdenas denunciaba el respaldo incondicional que la prensa le había dado al régimen autoritario imperante en Chile. Estos grandes medios se habían dedicado «a la siembra de ideas y su incontrarrestable cosecha de beneficios» (1984, p. 61). Aunque el autor no menciona nombres, sabemos claramente cuáles son esos medios que apoyaron a la dictadura incluso desde antes que ésta existiera.

Cárdenas hace hincapié en la manipulación que se llevó a cabo bajo este Orden Informativo, bajo esta peligrosa relación de Régimen-Prensa en la que mucho conocimiento del acontecer nacional e internacional le fue privado a la sociedad chilena, y en cómo se desvirtuó la realidad y la conciencia nacional. En este sentido, retoma la idea del discurso ideológico y polarizado de estos medios que «decidieron dividir la creación entre buenos y malos, entre orden y caos, entre luz y tinieblas, de manera tal de dar justificación plena a un nuevo génesis, esta vez con un paraíso muy estrecho y rodeado por un abismo sin salida» (Cárdenas, 1984, p. 62).

Durante la dictadura, los medios que apoyaban la ideología de derecha obtuvieron una gran parte del mercado de la prensa en Chile, y al regresar la democracia al país, los medios de izquierda no pudieron hacerles frente, desapareciendo por la falta de apoyo económico internacional, e incluso porque sus benefactores y columnistas nacionales dejaron de prestarles atención, dedicándose a ejercer cargos políticos de confianza y de elección popular. Para Dermota (2002), eso produjo que, en democracia, nuestros medios de comunicación sean de menor calidad, e incluso menos pluralistas que en la propia dictadura. Para el autor, en la actualidad, los políticos no han hecho nada para solucionar esta situación y sus intereses se encuentran alejados del apoyo a una prensa crítica audaz o de disidencia/oposición, sino que más bien dependen de los medios tradicionales como El Mercurio y La Tercera para posicionar su imagen frente al país.

\section{Periodismo de libre mercado}

Tristemente nos vemos enfrentados a un escenario en el que los medios de comunicación son actualmente regulados por las leyes de la mano invisible del mercado. Pero la experiencia nos dice que esa mano no es tan invisible y que forma parte del pensamiento conservador chileno. Décadas después de la transición a la democracia, la labor periodística y la vida social y política se rigen por la visión de los grupos empresariales El Mercurio y Copesa y no hay en la prensa muchas alternativas para una información de carácter progresista. Los mensajes fueron uniformándose y convirtiéndose en mercancía, y los ciudadanos, los lectores, dieron paso a los 
consumidores, pero ya no de información, sino de publicidad, que es el actual modelo de negocios desde el que se sostienen los medios de comunicación escritos en Chile. Y, de paso, se nos entrega un adoctrinamiento ideológico, todo por un mismo precio. Al respecto, Baltra señala:
para los grandes empresarios y su aliada, la publicidad, los medios son principalmente vehículos para ofrecer y colocar sus bienes o servicios. La actual prensa chilena parece centrada en cómo vender "productos" -que incluyen las noticias o informaciones- a un lector (cliente) aparentemente desideologizado, pero con mayor capacidad adquisitiva que en el siglo anterior (2012, p. 97).

Es más, autores como Pascual Serrano, sostienen que cuando los medios se valen de la publicidad, nosotros, el público, dejamos de ser consumidores, y nos transformamos en el producto de la transacción: «Si nos fijamos bien, comprobaremos que lo que venden los medios no es un buen contenido informativo, ellos venden audiencias, nos venden a nosotros a las agencias de publicidad» (2012, p. 31).

Pero la mano invisible regula lo que estima conveniente, y la realidad es que en Chile existe una perversa concentración mediática, que no da espacio a la diversidad ni al pluralismo informativo, cosa que no sólo es evidente en los medios de comunicación escritos, sino también en las radios y la televisión. Para María Olivia Mönckeberg (2013), la falta de pluralismo sigue siendo una espina clavada en nuestra democracia y se ha convertido en una característica endémica de los medios de comunicación chilenos.

Al regirse por las leyes del mercado, los medios de comunicación se transforman en empresas productoras de noticias, y las relaciones son verticales, siempre teniendo la última palabra los administrativos. Los que antes eran directivos con formación periodística, se han transformado en administradores de empresas e ingenieros comerciales. Y, como se mencionaba, el negocio en la actualidad no es la venta de los periódicos en sí, sino la venta de avisaje publicitario. La publicidad es en Chile la principal fuente de financiamiento de los medios de comunicación. En palabras de María Olivia Mönckeberg:

Se trata de una extraña situación en que quienes los gestionan tienen que pensar a la vez en dos tipos de «público»: el que lee, escucha o ve, y el que contrata los avisos. Poco a poco, este «segundo cliente» se ha vuelto determinante para la definición de los contenidos y las líneas editoriales (2013, p. 418). 
A modo de ejemplo, y según cifras de la Asociación Chilena de Publicidad (ACHAP) presentes en su último estudio de Inversión en Comunicación Publicitaria, en el año 2018 se invirtieron más de 618 mil millones de pesos en publicidad en Chile, que correspondería a más de 800 millones de dólares. De ellos, un 43,1\% se destinó a la televisión (266 mil 358 millones de pesos), un 22,3\% se destinó a los diarios (137 mil 991 millones de pesos), un 12,6\% a publicidad outdoor y un $11,6 \%$ a las radios. Cabe destacar que para el año 2018 no se consideró la publicidad online porque los medios de comunicación consultados no entregaron suficiente información, pero en el estudio del 2017 esta inversión alcanzó los 161 mil 276 millones de pesos.

En base a estas millonarias cifras, las direcciones de los medios de comunicación (y los propios editores y periodistas) toman decisiones ligadas más al mercado y a sus intereses económicos que al bienestar de los lectores y ciudadanos que necesitan ser informados, es decir, al interés social. De ahí que el público solamente interese en cuanto a consumidor de productos y servicios.

Cárdenas (2008) afirma que, en la sociedad chilena actual, los defensores del libre mercado piensan que éste debe regularlo todo, incluida la libertad de prensa. De ahí que nociones como rating y tiraje sean regidoras de los contenidos de los medios de comunicación y definan qué es noticia y qué no lo es. Según este autor, lo vulgar se ha tomado los contenidos y las imágenes de los medios, pues esto es lo que vende para los productores, publicistas y avisadores:

\footnotetext{
Para ganar audiencia, la máxima es, ahora, entretener a cualquier precio. ¿Cuál audiencia? Por cierto, la que tiene mayor capacidad de consumo. Y capacidad de consumo ¿para qué? Para obtener auspicios. Es decir, recursos para financiar en negocio (2008, p. 99).
}

Este autor destaca la falta de una legislación en Chile que sea capaz de regular la concentración de los medios y de garantizar la representatividad, el pluralismo y la diversidad en el sistema informativo, evitando además la extranjerización de nuestros medios de comunicación: «Al dios Mercado no se le debe tocar; la libertad de prensa es un derecho patronal de quienes pueden financiar el gusto de modelar la conciencia popular, influir en sus actos y seducir a los políticos» (Cárdenas, 2008, p. 102).

Según las observaciones de campo de Dermota (2002), los periódicos en Chile funcionan bajo una lógica autoritaria de fundo, y las relaciones jerárquicas se dividen entre el jefe y los obreros, dando cabida a una profunda división de clase en las salas de redacción, en donde los 
editores tienen el control de los temas e incluso de las fuentes que deben citar los periodistas, interviniendo en el producto final de la noticia publicada.

La consecuencia es un periodismo cauto, no dinámico ni comprometido, ni siquiera interesante, y que no entrega la información que necesita una democracia emergente para engendrar un debate público serio e informado. El fundo de la sala de redacción es instrumental para la promoción de los intereses y la agenda de los dueños de los medios (Dermota, 2002, p. 252). Los periodistas, como trabajadores de la información, nos hemos vuelto parte de estas prácticas. Nuestra precaria situación laboral no da espacio a ninguna contradicción o a voces críticas. Pasivos, y en consecuencia con la ideología del medio, guardamos silencio o nos autocensuramos, evadiendo temas que puedan dañar o disgustar a los avisadores, socios 0 dueños.

Según Serrano (2011), el problema del periodismo desarrollado en una economía neoliberal es que en ella los profesionales nunca son verdaderamente libres. Para el autor, el control incluso de la propia ética del periodista está en manos de quien lo contrata, que es el mismo que tiene también el poder para despedirlo si no acata la ideología del medio. Al respecto, Cárdenas considera que el mercado ya ha demostrado su incapacidad de proveer justicia social. Un periodismo independiente de la mano del mercado sería necesario para la democracia genuina:

\begin{abstract}
¿Es posible que alguien todavía piense que el mercado restituya a los medios su misión de informar, educar y entretener sanamente? ¿Es posible que en el actual desorden de las cosas los medios pueden recuperarse para su tarea de ser alicientes en la tarea que a todos nos compete de comprender el mundo y participar en la construcción de una sociedad más libre y solidaria? (2008, p. 103).
\end{abstract}

\title{
A modo de conclusión
}

Cuestionando la misión del periodismo, se puede sostener que éste ha dejado de lado su compromiso público. Su visión social se ve constantemente relegada por una actitud cómoda y neutral, que no se compromete con la gente. Los medios de comunicación contienen ideologías, ocultas bajo la máscara de la objetividad, y van descontextualizando los propios acontecimientos, restándoles el conflicto y las contradicciones, banalizando luchas sociales y poniendo en el centro del interés público las anécdotas y la entretención, el fútbol y la farándula. Estos discursos tienden a parecer más propaganda o publicidad que verdadera información útil para los ciudadanos y que vele por la construcción de una sociedad más justa para todos. 
Aunque aun puede parecer algo lejano para la realidad chilena, en muchos países del primer mundo, el periodismo impreso se está debilitando. Muchos grandes y tradicionales periódicos están en crisis económica, puesto que la publicidad ya no puede sostenerlos en un mundo tecnológico, en el que las personas hiperconectadas prefieren informarse en internet y sin la necesidad de pagar. Esto ya sucedió en Estados Unidos (dónde los medios impresos se habían desarrollado en toda su potencialidad) y está aconteciendo en Europa.

En general, la plataforma impresa, está destinada a desaparecer. Ya sean libros, revistas o periódicos. Lo que está fuera de discusión es que la gente va a continuar teniendo la necesidad de estar informada, y que, a pesar de no existir la posibilidad de comprar el diario cada mañana en el quiosco de la esquina, los periodistas van a seguir existiendo. Pero van a experimentar numerosas transformaciones.

Un punto importante de destacar es que, por sobre la modernización de los medios de comunicación o la crisis del oficio periodístico, los que han cambiado son los lectores. Más críticos, más conscientes y con más herramientas, en las sociedades occidentales podemos «pensar que son ellos y no los periodistas los que están protagonizando el cambio. Los medios cambian porque quienes los consumen y usan quieren que cambien» (Bassets, 2013, p. 15).

El futuro del periodismo se encuentra en la convergencia de formatos, lo que también se conoce como multimedialidad (e incluso transmedialidad). El texto, el formato en papel e impreso, es inútil y resulta aún más efímero que el código binario en una pantalla. Lluís Bassets (2013) incluso llega más lejos y señala que ya no podemos hablar de medios de comunicación, puesto que éstos no están mediando, porque las tecnologías están ahora en manos del público. Y es el mismo público el que no quiere ningún tipo de mediación, puesto que el medio mismo se ha transformado en la realidad social.

Haciendo referencia a la crisis de los medios de comunicación tradicionales, Serrano (2011) indica que, para él, la crisis de la prensa tiene una doble cara, la de la caída de las ventas, pero también la caída de las publicidades. Y esta doble crisis se transforma en un círculo vicioso, pues los periódicos, al no tener recursos para financiar reportajes de gran calidad 0 corresponsales y enviados especiales, no son atractivos para los lectores que exigen excelencia y profundidad.

Ya en 1967, Umberto Eco reflexionaba en torno a las posibilidades frente a la dominación provocada por los medios de comunicación. Mencionando a McLuhan, señala que los medios han dejado de ser una herramienta para producir bienes económicos, para transformarse en el principal bien económico.

Ante la nueva forma de sentir y experimentar la realidad a través de los medios de comunicación, en los que se transmiten ideologías (para los apocalípticos, los medios son la 
ideología en sí mismos), Eco cree que la forma de luchar contra el poder no es intentando controlar ni la fuente, ni el canal para controlar los mensajes. Lo que este autor propone es, más bien, preocuparnos, por, sobre todo, del destinatario. Esto es lo que el autor llama una solución de guerrilla de la comunicación:

la batalla por la supervivencia del hombre como ser responsable en la Era de la Comunicación no se gana en el lugar de donde parte la comunicación sino en el lugar a donde llega (...) en el momento en que los sistemas de comunicación prevén una sola fuente industrializada y un solo mensaje, que llegaría a una audiencia dispersa por todo el mundo, nosotros debemos ser capaces de imaginar unos sistemas de comunicación complementarios que nos permitan llegar a cada grupo humano en particular, a cada miembro en particular, de la audiencia universal, para discutir el mensaje en su punto de llegada, a la luz de los códigos de llegada, confrontándolos con los códigos de partida (2012, p. 186).

Completamente visionario ante el futuro de los medios de comunicación, Eco hace hincapié en la fuerza de las múltiples interpretaciones como una vía de acción para que el público controle el mensaje. Esta táctica de guerrilla puerta a puerta sugiere, por ejemplo, la posibilidad de que un medio pueda utilizarse para emitir juicios sobre otro, y desmentir o confrontar información o códigos, como, por ejemplo, se consigue en internet y redes sociales frente a los medios de comunicación tradicionales y masivos.

Frente a los recientes estallidos sociales en Chile, desde octubre de 2019, hemos visto cómo los medios representantes de este periodismo de libre mercado (como la prensa y la televisión) nuevamente no han sabido enfrentar con profundidad y contexto las demandas de la ciudadanía, criminalizando (como ya es costumbre) la protesta y las manifestaciones. La gente ha preferido los medios alternativos para informase, y han cobrado fuerza los medios independientes en internet y la comunicación comunitaria en las redes sociales.

Al respecto, entendemos que lo que las audiencias buscan es un periodismo comprometido con la gente, medios de comunicación que permanezcan independientes de la mano del mercado, que sean sinceros y transparenten sus intereses abiertamente. Medios que vayan más allá de la farándula y el sensacionalismo, que entreguen una mirada pluralista de la realidad social y que colaboren con la construcción de la cohesión y la justicia social.

\section{Referencias bibliográficas}


Asociación Chilena de Publicidad (2019). Inversión en Comunicaciones Publicitarias 2018. Santiago de Chile, Chile. Recuperado de

http://www.achap.cl/wp-content/uploads/2019/07/Inversion-ACHAP-2018-2.pdf

Baltra, L. (2012). La prensa chilena en la encrucijada. Entre la voz monocorde y la revolución digital. Santiago de Chile, Chile: LOM.

Bassets, L. (2013). El último que apague la luz. Sobre la extinción del periodismo. Madrid, España: Taurus.

Bourdieu, P. (1997). Sobre la televisión. Barcelona, España: Anagrama.

Cárdenas, J. (1984). Por un Chile libre. Santiago de Chile, Chile: Editorial Emisión.

Cárdenas, J. (2008). El periodismo comprometido. Santiago de Chile, Chile: Ediciones Radio Universidad de Chile.

Dermota, K. (2002). Chile inédito. El periodismo bajo democracia. Santiago de Chile, Chile: Ediciones B.

Eco, U. (2012). La estrategia de la ilusión. Barcelona, España: Random House Mondadori.

Foucault, M. (1992). El orden del discurso. Buenos Aires, Argentina: Tusquets Editores.

García, J. (2013). Revolución, socialismo, periodismo. La prensa y los periodistas cubanos ante el siglo XXI. La Habana, Cuba: Pablo de la Torriente Editorial.

Lagos, C. (2009). El diario de Agustín. Cinco estudios de casos sobre El Mercurio y los derechos humanos (1973-1990). Santiago de Chile, Chile: LOM.

Mattelart, A.; Piccini, M. y Mattelart, M. (1976). Los medios de comunicación de masas. La ideología de la prensa liberal. Buenos Aires, Argentina: Schapire -El Cid.

Mönckeberg, M. (2013). Los magnates de la prensa. Concentración de los medios de comunicación en Chile. Santiago de Chile, Chile: Random House Mondadori.

Orellana, A. (2016). El lapidario informe sobre la concentración mediática en Chile que el CNTV mantiene en reserva. El Desconcierto. Recuperado de

https://www.eldesconcierto.cl/2016/11/30/el-lapidario-informe-sobre-la-concentracion-mediaticaen-chile-que-el-cntv-mantiene-en-reserva/

Rodrigo Alsina, M. (2005). La construcción de la noticia. Nueva edición revisada y ampliada. Barcelona, España: Paidós.

Romero, P. (2013). Análisis crítico de la representación informativa de Camila Vallejo y el Movimiento Estudiantil chileno 2011 en el diario Las Últimas Noticias. Revista Estudios sobre el Mensaje Periodístico, Vol. 19, Núm. 2 (2013), 871-888.

Santander, P. (2009). Por qué, para qué y cómo hacer Análisis del Discurso en los medios de comunicación. En Santander, P. (Editor): Analizando los medios y la comunicación: teoría y métodos. Valparaíso, Chile: Ediciones Universitarias de Valparaíso. 
Serrano, P. (2011). El periodismo es noticia. Tendencias sobre comunicación en el siglo XXI. Quito, Ecuador: Editorial Quipus-CIESPAL.

Serrano, P. (2012). Desinformación. Cómo los medios ocultan el mundo. Barcelona, España: Ediciones Península.

Van Dijk, T. (2006). Ideología. Una aproximación multidisciplinaria. Sevilla, España: Gedisa.

Vera, H. (2008). Estrategias de construcción de noticias. En Browne, R.; del Valle, C.; Mayorga, J.; Nitrihual, L. y Silva, V. (Coord.): Contrapuntos y Entrelíneas sobre Cultura, Comunicación y Discurso. Temuco, Chile: Ediciones Universidad de La Frontera. 